\title{
Aquelarre. La emancipación de las mujeres en la cultura de masas
}

\section{Coven. The emancipation of women in mass culture}

Fechas | En edición: 14/05/2020 - Publicación final: 01/01/2021

\section{Laura MANZANO-ZAMBRUNO}

Universidad de Sevilla. España. lauramanzam@gmail.com

\section{Aquelarre. La emancipación de las mujeres en la cultura de masas}

Coordinadoras: Irene LIBERIA-VAYÁ; Bianca SÁNCHEZ-GUTIÉRREZ.

Sevilla: Advook, 2020.

256 páginas

ISBN: 978-84-942969-9-4.

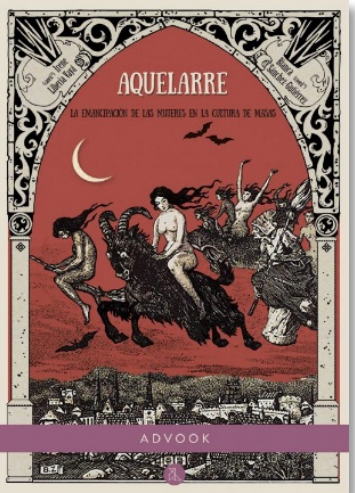

\section{Resumen}

Aquelarre. La emancipación de las mujeres en la cultura de masas es una obra coral compuesta por diez capítulos que analizan diez ámbitos de la llamada cultura de masas desde una perspectiva crítica. Marca un objetivo y una pregunta de investigación en su introducción que se concreta en otros específicos en cada capítulo, lo que convierte este libro en una propuesta compacta y solvente. En sus páginas procuran catalogar, y lo hacen con éxito, estos sectores en función de la ayuda o el obstáculo que prestan a la consecución de la liberación de las mujeres y la igualdad entre sexos.

\section{Palabras clave}

Cultura de masas; estereotipos; feminismo; género; medios de comunicación; neoliberalismo.

\begin{abstract}
Coven. The emancipation of women in mass culture is a choral work developed throughout ten chapters that analyses from a critical perspective ten aspects of the so called mass culture. Both the aim and the research question proposed within the introduction will be more specifically targeted chapter by chapter, what makes this book a compact and solvent approach. Its pages seek to successfully catalogue these aspects depending on whether they entail an aid or an obstacle as a means to achieving women's liberation and gender equality.
\end{abstract}

\section{Keywords}

Mass culture; stereotypes; feminism; gender; neoliberalism; media. 
Aquelarre. La emancipación de las mujeres en la cultura de masas (Aquelarre en adelante) es una obra compuesta por diez capítulos elaborados por diferentes autoras, que analiza, como bien indica su título, la relación entre la cultura masas y la liberación de las mujeres. Cada parte se aproxima a un sector delimitado: literatura, revistas femeninas, periodismo, radio, música, cine, televisión, publicidad, videojuegos e Internet. Irene Liberia-Vayá y Bianca Sánchez-Gutiérrez se han enfrentado como coordinadoras al reto de otorgar entidad a un proyecto coral, superándolo con éxito si te tiene en cuenta que, salvo excepciones, los contenidos están orientados en la misma dirección, que no hay solapamientos a pesar de que los ámbitos temáticos son muy cercanos y que los capítulos se hacen mención entre sí, lo que mejora la compactación del libro.

Su estructura está bien definida e incluye objetivos y preguntas de investigación. En la introducción, LiberiaVayá y Sánchez-Gutiérrez formulan un objetivo general para los capítulos venideros, "situar a los medios de comunicación y a la cultura de masas en el contexto de la lucha por la igualdad sexual" (2020: 30), y una pregunta también común, cómo los distintos sectores que se analizan "han contribuido y contribuyen a que las mujeres seamos más o menos libres hoy" (2020: 31). Particularmente, la mayoría de autoras plantea objetivos y preguntas específicas, y organiza el contenido conforme a un esquema estable consistente en el desarrollo de un breve contexto, un marco teórico o una presentación de conceptos clave, y un estudio de caso.

El posicionamiento intelectual del libro se hace explícito desde las primeras páginas y ofrece, con ello, limpieza y honestidad a la exposición. Aquelarre se ubica dentro de la perspectiva crítica del feminismo, oponiéndose al neoliberalismo y abogando por un análisis de tradición marxista de la cultura mediática (Liberia-Vayá y Sánchez-Gutiérrez, 2020: 27-28). En el prólogo, Pilar Aguilar Carrasco enmarca esta obra dentro del materialismo, consciente de que "Ia materia es", si bien "la realidad es una construcción nuestra" (2020: 19). Es precisamente en la elección de hablar de sistema "sexo/género", y no de género a secas, que se puede percibir el compromiso de Aquelarre con esta postura materialista.

Si bien éstas son las características generalizadas, han de señalarse dos capítulos que se distancian de ellas. En el quinto capítulo, centrado en el acceso de las mujeres a la música popular, la perspectiva crítica se diluye debido a algunos planteamientos. Por ejemplo, parece legitimarse la representación de la violencia hacia los hombres por parte de mujeres (en este caso concreto, en un videoclip) como una vía para la liberación femenina, mecanismo que, realmente, no vendría a subvertir el sistema, sino a invertirlo. Esta aseveración se acompaña de una cita que visibiliza otra interpretación, ésta sí crítica, que se ofrece más como contraste que como contraargumento. En el caso del capítulo noveno, sobre videojuegos, lo que se acusa es la falta de estructura a la que se adhieren los demás, reflejada, por ejemplo, en una relación de hitos de mujeres pioneras en el sector situada al final del capítulo, y en la ausencia de objetivos, preguntas de investigación y un análisis de caso concreto.

Cabe destacar tres capítulos por representar el espíritu crítico que se manifiesta en la introducción. El segundo, sobre revistas femeninas, ejecuta su análisis planteándolas como productos de consumo que, a día de hoy, se enfrentan a la pregunta de qué es lo femenino en medio de un panorama social que está redefiniendo la relación sexo/género. Estas revistas han optado por crear una ficción representada por una "mujer catálogo" que encarna el ideal de belleza normativo. Sobre la belleza habla también el séptimo capítulo, centrado en los estereotipos que perpetúan los reality shows televisivos, concretamente en el subgénero del makeover y el programa Cambio Extremo, donde se evidencia que el mayor peso de encajar en unos estándares físicos recae sobre las mujeres. Los productos televisivos de este tipo las responsabilizan de no encajar en el canon, alimentando la falacia de la libertad de elección, y sacralizan la cultura de la transformación del cuerpo, que convierte la cirugía estética en un bien de consumo más. Por último, el octavo capítulo, sobre publicidad y feminismo, merece mención por ser el que ofrece una delimitación más clara de conceptos y enfoques, abordando qué se entiende en el texto por publicidad, cuál es su posicionamiento feminista concreto y cuál su objetivo de investigación. Es especialmente interesante su propuesta de análisis de distintas campañas publicitarias, atendiendo al tipo de patriarcado en el que están contextualizadas.

Se echan en falta unas conclusiones generales que valoren en qué medida se han cumplido los objetivos y reflexionen sobre los puntos en común entre los capítulos. A este respecto, destaca el hecho de que la mitad de ellos aborden la presencia minoritaria de las mujeres en sus respectivos ámbitos y traten cuestiones como la desigualdad de salarios o el techo de cristal; y que también otros cinco coincidan en enarbolar la importancia del rescatar el trabajo de muchas mujeres. La cuestión de los estereotipos y la sexualización de las mujeres es, sin duda, la más repetida, por lo que hubiera sido interesante compararla. Por último, quizá una de las oportunidades más relevantes para un apartado de conclusiones hubiera sido un análisis conjunto de las reacciones machistas despertadas en cada ámbito, de las cuales hablan todos los capítulos. Comentan Sonia Reverter y María Medina-Vicent que el "antifeminismo también se puede relatar en olas, pues para cada ola feminista hay una reacción organizada en contra" (2020: 9). Podría 
haber sido éste un primer paso para caracterizar en mayor detalle la ola antifeminista que está acompañando a esta cuarta ola del feminismo.

Aquelarre es, en definitiva, un libro que hace un esfuerzo fructífero por recopilar, desde un enfoque crítico, análisis sobre distintos ámbitos de la cultura de masas y reflexionar sobre su contribución al feminismo. Se trata de una obra especialmente recomendable para quienes deseen aproximarse a esta línea de trabajo y conocer la riqueza de posibilidades que ofrece.

\section{Referencias bibliográficas}

[1] Aguilar Carrasco, P. (2020). Prólogo. En Liberia-Vaya, I. y Sánchez-Gutiérrez-B. (coords.), Aquelarre. La emancipación de las mujeres en la cultura de masas (pp.19-21). Sevilla: Advook.

[2] Liberia-Vayá, I. y Sánchez-Gutiérrez, B. (2020). Introducción. En Liberia-Vaya, I. y Sánchez-Gutiérrez-B. (coords.), Aquelarre. La emancipación de las mujeres en la cultura de masas (pp.23-37). Sevilla: Advook.

[3] Reverter, S. y Medina-Vicent, M. (2020). El feminismo en 35 hashtags. Madrid: Lo libros de la Catarata. 